\title{
MODELOS DE NEGÓCIOS SUSTENTÁVEIS: A ABORDAGEM PROJETUAL DO DESIGN ESTRATÉGICO, VALORIZAÇÃO DE PRODUTOS LOCAIS
}

SUSTAINABLEBUSINESSMODELS: THEPROJECT APPROACHOFSTRATEGICDESIGN TO CREATEVALUE ON LOCAL PRODUCTS

\section{Pablo Bezerra, M.Sc. (UFPE); Amilton Arruda, Dr. (UFPE); Isabela Moroni, M.Sc. (UFPE); Theska Soares, M.Sc. (UFPE)}

\author{
Palavras Chave \\ Design Estratégico; Sustentabilidade; Modelo de Negócio; Produto Local;
}

\section{Key Words}

Strategic Design; Sustainability; Business Model; Local Product

\section{RESUMO}

Em um contexto de alta competitividade e escassez de recursos, a busca da criação de modelos de negócio sustentáveis é fundamental para que organizações se destaquem e tenham longevidade no mercado. Tal ideal deve estar presente em tudo que a envolve, incluindo seus processos e produtos. O presente artigo visa refletir sobre o poder da adoção da abordagem de Design Estratégico na criação e aplicação de modelos de negócio baseados em produtos locais - importantes motores para o desenvolvimento econômico de suas regiões. Para tanto realizou-se uma pesquisa bibliográfica e foi analisado um estudo de caso. O Design Estratégico, como uma abordagem projetual que objetiva conceber Sistemas Produto-Serviço pautados pela sustentabilidade e fieis a uma estratégia organizacional bem definida, apresentou-se como um recurso de alto potencial para auxiliar na consolidação dos modelos de negócio sustentáveis e sua aplicação em tudo aquilo que uma empresa se propõe a fazer e comunicar.

\section{ABSTRACT}

In a context of high competitiveness and shortage of resources, creating sustainable business models is crucial for organizations that seek to stand out and have longevity in the market. Such an ideal must be present in everything that involves the company, including its processes and products. This article aims to reflect on the power of adopting the Strategic Design approach in the creation and application of business models based on local products - which are important engines for the economic development of their regions. For this, a bibliographic review was carried out and a case study was analyzed. Strategic Design, as a project approach that aims to design Product-Service Systems based on sustainability and aligned to a well-defined organizational strategy, has presented itself as a resource with high potential to assist in the consolidation of sustainable business models and their application in everything that an organization aims to do and communicate. 


\section{INTRODUÇÃO}

Durante o seu processo evolutivo, o Homem aprendeu a conviver com a natureza e a extrair dela o necessário para sua sobrevivência e prosperidade. Com o domínio de algumas técnicas e a criação de ferramentas, foi possível para os povos aproveitar o máximo do seu ambiente, produzindo bens e confeccionando artefatos que ajudariam a moldar sua identidade cultural e suas vocações econômicas, tornando-os conhecidos além de suas fronteiras a partir dos produtos que conseguiam produzir e, alcançando prosperidade e um status de excelência no tocante àquele bem. Consequentemente, ao longo dos séculos, patrimônios culturais que se consolidaram e passaram a definir cada povo - sendo expressos em suas produções econômicas e sociais - tornaram-se elementos de alto valor simbólico e começaram a ser cada vez mais estimados na contemporaneidade, onde a alta oferta de produtos e serviços demanda dos fabricantes a busca pela diferenciação.

Nesse contexto os produtos locais surgem como uma modalidade de oferta única e fundamental para a prosperidade tanto dos produtores e fabricantes, quanto, especialmente, das suas comunidades. Como afirma Krucken (2009), valorizar o produto local significa trazer prosperidade para o seu território de origem, fomentando o benefício de uma rede de agentes envolvidos, desde a comunidade produtora até os consumidores usuários. Segundo a autora, esse processo se dá à medida que o produto "conta a história" de sua região, tornando-se uma expressão de sua identidade e possibilitando que o consumidor os enxergue e aprecie de maneira diferente, entendendo-os como singulares, especiais e que contribuem para a qualidade de vida das pessoas que trabalharam para produzir aquele bem e/ou habitam aquela localidade.

Torna-se, assim, essencial a presença de iniciativas que ajudem a identificar e desenvolver as vocações de uma região sob um aspecto holístico, ou seja, considerando todos os envolvidos. Tal amplitude é importante pois a presença desses atores, com toda a sua vivência e relação com a história e a cultura daquele local, será determinante para que sejam encontrados, compreendidos e estimados os valores culturais que deverão estar representados nas ofertas econômicas. Sob esse prisma, identificar e valorizar traços socioculturais torna-se fundamental, pois "aspectos não econômicos contribuem para o desenvolvimento econômico regional, particular-mente as práticas culturais regionais e locais" (VIEIRA; SANTOS, 2012).

Em um contexto de alta competitividade, onde empresas e territórios devem buscar prosperidade a partir de ofertas de alto valor percebido, torna-se cada vez mais importante que a criação de empreendimentos e produtos seja feita de maneira estratégica, ou seja, considerando "o que se quer ser" e "onde se quer chegar", bem como quais os recursos disponíveis e necessários para se atingir tal propósito.

Assim, surge a necessidade de se projetar melhores soluções para os problemas cotidianos e novas oportunidades de alcançar e cativar os indivíduos. No tocante às relações comerciais, é necessário ler cada vez melhor o ambiente e entender o que as pessoas querem e necessitam para melhorar sua qualidade de vida. Para este fim, o Design surge como um campo de alto potencial na busca pela qualidade e inovação.

$\mathrm{Na}$ busca pela quebra de paradigmas que reduzem o Design a uma ferramenta de intervenção estética, muitas vezes relegada a fases posteriores no processo de criação de empresas e suas ofertas, surgem estudos que buscam entender o potencial transformador do Design em um espectro maior e ajudar na sua melhor inserção nas organizações não apenas em nível operacional, mas também tático e estratégico. Destaca-se o Design Estratégico, abordagem projetual que objetiva integrar o processo de concepção do Sistema Produto- Serviço (SPS) às ambições estratégicas da organização, primando pela busca de soluções relevantes e pela sustentabilidade.

Pretende-se demonstrar que o pensamento projetual e a busca por alternativas criativas e embasadas em uma leitura coerente da realidade pode trazer benefícios em níveis operacionais, táticos e estratégicos. Fundamentalmente, o Design Estratégico, foco do presente artigo, trabalha no alinhamento entre os direcionamentos estratégicos da organização e a concepção de suas expressões (produtos, serviços e sistemas comunicacionais), buscando imprimir valor e identidade aos projetos, reforçando o compromisso estratégico das empresas. Assim, tal abordagem projetual apresenta alto potencial na criação de modelos de negócio diferenciados, especialmente na busca por um sistema sustentável.

Para tanto, realizou-se uma pesquisa exploratória de base documental e caráter observacional - com a coleta e análise de materiais diversos fornecidos pela organização, matérias e entrevistas divulgadas na imprensa especializada e exploração dos canais de comunicação da marca com o público - aliada a uma revisão bibliográfica (GIL, 2008), onde foram estudados os princípios teóricos relevantes dentre os temas escolhidos. 


\section{COMPETITIVIDADE E ESTRATÉGIA}

Qualquer empreendedor que deseja oferecer um produto ou serviço encontra uma realidade onde as decisões empresariais devem ser mais bem estruturadas, desde a concepção e formatação de um negócio até a oferta chegar às mãos dos consumidores, passando por um sem-número de processos e agentes que serão determinantes no cálculo de seus custos e, assim, na sua competitividade. Essas decisões devem ter como elemento norteador uma bem-concebida estratégia.

Fundamentalmente, o papel da estratégia está ligado à busca da vantagem competitiva, assim definida:

Uma empresa tem vantagem competitiva quando implementa uma estratégia que os concorrentes não conseguem copiar ou acham custosa demais para imitar. Uma organização só pode ter certeza de que sua estratégia resultou em uma ou mais vantagens competitivas úteis quando os esforços dos concorrentes para copiá-la pararam ou fracassaram. Além disso, as empresas têm de entender que nenhuma vantagem competitiva é permanente. (HITT; IRELAND; HOSKISSON, 2011, p. 4)

Em um processo claramente dinâmico e complexo, a eficiente criação e implantação de uma estratégia passa por uma necessidade de mentalidade e atitude adequadas para poder enfrentar os obstáculos impostos pelo ambiente, com o direcionamento para a busca de uma vantagem sustentável. Um aspecto básico e fundamental está ligado à forma como o empreendedor/executivo enxerga e encara o amanhã.

Essencialmente, existem três tipos de atitude em relação ao futuro. $O$ pensamento tradicionalista valoriza fortemente as vivências passadas, tirando das experiências, de sucesso ou não, as lições para por quê, o quê, como e quando fazer as coisas. $O$ gestor tradicionalista conduz as suas decisões replicando o que já deu certo e evitando aquilo que deu errado. Essa atitude torna-se perigosa em virtude da realidade mutante em que vivemos.

$\mathrm{O}$ contexto de cada momento não nos garante que o sucesso ou fracasso do passado se repetirá no futuro. Já a atitude pragmática dá grande importância aos eventos, dados e fatos do presente. Esses gestores costumam embarcar em modismos, atuando fundamentalmente de forma reativa ao que ocorre à sua volta.

Em países considerados em desenvolvimento, como - Brasil, essa prática é muito comum, especialmente à medida que as pessoas atualmente têm acesso mais fácil àquilo que podem tentar replicar (COSTA, 2007). Embora importante buscar referências e reproduzir boas práticas, negócios com essa característica enfrentam uma grande quantidade de concorrentes que também copiaram das mesmas fontes inspiradoras. Essa falta de diferenciação, leva novamente à temida competição baseada no preço, diminuindo o valor e iminentemente extinguindo grande parte das empresas. Por fim temos a atitude estratégica:

Esse processo consiste, exatamente, em um exercício de se transportar mentalmente para um futuro desejável, considerado possível, e a partir de lá olhar para trás, para o hoje, e perguntar o que deve ser feito no presente para que o idealizado no futuro se concretize. [...] a visão estratégica que se pretende criar consiste em desenvolver a capacidade de olhar, criticamente, o presente a partir do futuro, e não o futuro com os olhos do presente (!). Esse é o grande desafio a vencer. A construção desse novo modelo mental pode ser efetivada e enriquecida se for realizada com equipes multiníveis e interfuncionais, e não individualmente. (COSTA, 2007, p. 13)

Esse modo de observar o contexto, costuma trazer insights diferenciados, que tornarão cada negócio distinto à sua maneira e dificultarão a destruição do seu valor, isso acontece pois mesmo que alguém resolva copiá-lo, ele será valorizado como "o original". Além disso, copiar demanda tempo e investimento por parte do concorrente, o que também atrapalha o seu sucesso. A Figura 1 condensa as principais características de cada forma de agir.

Figura 1: Atitudes Tradicionalista, Pragmática e Estratégica.

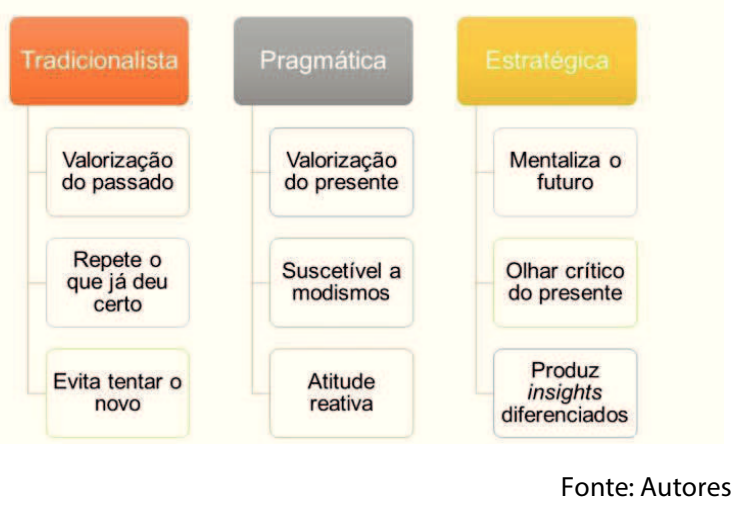

A importância desses elementos de raiz psicológica é justificada pelas frequentes restrições e obstáculos que os gestores enfrentam no processo de gestão 
estratégica. Obstáculos culturais - dificultando a percepção da necessidade e benefícios de correr certos ris$\cos$-, organizacionais - onde muitas empresas são excessivamente burocráticas ou departamentalizadas, por exemplo - e gerenciais são comuns e o líder deve ser capaz de transmitir segurança e crédito para que os seus pares e subordinados embarquem no direcionamento estratégico proposto. Essa crença verdadeira e apoio dos colaboradores à sua liderança e à estratégia traçada são fundamentais para que o cliente perceba de forma substancial o valor que a empresa e suas ofertas estão oferecendo. Entende-se, assim, que a correta formulação e implantação de uma estratégia é uma atividade complexa e fundamental nas organizações.

\section{INSERINDO O DESIGN}

A estratégia, como um conceito, deve dirigir a empresa, seus colaboradores e, fundamentalmente, deve estar representada de maneira clara em seus produtos, ambiente, marca e tudo o que envolve o diálogo com o seu público. É especialmente, porém não exclusivamente, nesse estágio onde o Design apresenta-se como um recurso capital para as organizações.

Como atividade, o Design enfrenta uma incompreensão generalizada que contamina o mercado e dificulta a sua valorização e melhor utilização. Como afirma Bonsiepe (2011), a noção do Design como uma ferramenta de solução de problemas foi substituída pela ideia do "efêmero, da moda, do obsoletismo rápido". Em razão da popularização dessa linha de pensamento e a consequente banalização do termo "Design", a sua inserção nas instituições tornou-se limitada e o seu potencial total raramente explorado, sendo constantemente requisitado apenas no fim do processo de desenvolvimento dos produtos - quando as principais decisões estratégicas já foram tomadas e o que restam são deliberações acerca de retoques superficiais - ou em situações emergenciais, com o objetivo de tardiamente tentar reverter um quadro de fraco desempenho de mercado (BONSIEPE, 2015).

No entanto, os esforços acadêmicos em disseminar a pluralidade da disciplina e o próprio mercado mostram que o designer, atuando em conjunto com os demais colaboradores, oferece uma visão e uma capacidade de leitura das situações e proposição de soluções diferenciadas, uma vez que o processo de Design, como uma atividade multidisciplinar e iterativa, vai além da criação de soluções visuais, integrando e se relacionando com pesquisas de mercado, estratégia de marketing, criação e gestão de marcas, engenharia, desenvolvimento de produtos, planejamento de produção, distribuição e políticas de comunicação corporativa (MOZOTA, 2011). Encarando a atividade dessa maneira, a organização sai do modelo de negócio tradicional descrito por Kotler e Keller (2006) - onde a empresa faz "alguma coisa" e vende - para outro em que utiliza do Design em toda a sua plenitude para projetar a sua oferta da melhor forma, de modo a verdadeiramente oferecer um valor a ser reconhecido e apreciado pelo público. Esse reconhecimento tende a levar à fidelidade do consumidor, que será crucial para os resultados comerciais e a consequente saúde financeira da empresa e evolução do negócio.

\section{DESIGN ESTRATÉGICO}

O Design consolidou-se no século 20 como uma atividade importante para a identificação e solução de problemas do cotidiano das pessoas e o designer tornou-se um profissional com capacidade diferenciada de leitura das situações e ideação de alternativas.

No entanto, nas últimas décadas a profissão sofreu com uma interpretação errônea de suas principais qualidades e propósitos, sendo entendida como uma atividade ligada fundamentalmente a intervenções estéticas, noção que ganhou corpo com ajuda da mídia e do comércio "desinformado" que começou a adicionar o termo "Design" para evocar a estilo (BONSIEPE, 2011).

Entendendo, porém, que essa ideia precisava ser refutada e que as organizações precisavam entender o real potencial do Design e dos seus profissionais, iniciaram-se, no fim do século 20, movimentos e estudos que tinham como objetivo entender e sistematizar formas de como a área do Design poderia contribuir para as instituições em níveis e segmentos diversos. Surgem assim as bases disciplinares e intelectuais da Gestão do Design e do Design Estratégico, esse a partir dos estudos realizados pelos pesquisadores do Politécnico di Milano, especialmente Mauri, Manzini e Zurlo (FREIRE, 2015). Tais campos de estudo visam modificar a impressão das instituições sobre o Design, quebrando o paradigma de que o designer deve ser convocado para realizar atividades incrementais e estéticas.

Entendendo a importância do Design e incluindo-o nos processos de planejamento e decisão das ações organizacionais, a empresa já apresenta um potencial para melhoria em sua leitura das situações e a posterior criação de alternativas para resolução de problemas e para a continuidade dos seus planos. Esse cenário é fundamental para o melhor alinhamento entre o conceito abraçado pela instituição, o plano estratégico traçado e a sua tangibilização. Tal caminho, que consiste no núcleo processua 
responsável pela criação de uma oferta de valor, tem merecido um olhar atento de acadêmicos e profissionais a fim de descobrir como conceber produtos e serviços de alto potencial. Tais estudos levaram ao surgimento de uma linha de pesquisa que vem ganhando destaque nos últimos anos: o Design Estratégico (DE).

O DE surge para auxiliar os profissionais e organizações a transformarem suas visões em realidade, com o melhor aproveitamento dos recursos (financeiros, pessoais e ambientais) na criação de ofertas coerentes com aquilo que a empresa acredita - e é -, bem como com o que um público, cuidadosamente identificado, considera de valor. Um conceito, um planejamento processual, uma estrutura empresarial, tudo isso existe para apoiar uma atividade básica: oferecer algo que alguém necessite, da melhor maneira possível. Logo, para que o processo seja realizado corretamente, é necessário que exista o total alinhamento deste com a estratégia organizacional previamente criada e o conceito que deseja ser construído, materializado e comunicado ao público.

Tal coerência será aplicada não apenas na concepção da oferta, mas sim em todo o Sistema Produto-Serviço (SPS), que, por sua vez, consiste em um mix entre produtos, serviços, comunicação e pessoas. O DE de um SPS altera o foco de inovação do artefato para uma estratégia integrada de produto-serviço, orientado a produzir soluções (MERONI, 2008). A mudança de mentalidade - da criação de produtos para o Sistema Produto-Serviço, faz com que seja possível o estabelecimento de uma nova relação entre cliente instituição (MANZINI; VEZZOLI, 2002). Sobre o foco do DE, Meroni (2008) diz:

[...] there is a clear focus on the Product Service System (PSS) dimension, an orientation towards different kinds of social and market actors, a clear intention to produce innovation, and an emphasis on a systemic interpretation of sustainable development. [...] strategic Design is about conferring to social and market bodies a system of rules, beliefs, values and tools to deal with the external environment, thus being able to evolve (and so to survive successfully), as well as maintaining and developing one's own identity. And, in doing so, influencing and changing the environment too. (MERONI, 2008, p. 32)

Percebe-se, assim, no DE, além do olhar mercadológico, um direcionamento à busca da inovação e sustentabilidade como partes integrantes da identidade organizacional e como diferenciais competitivos valorizados pelos consumidores e demais stakeholders. Esse aspecto é parte importante no desenvolvimento de um SPS, visando garantir que uma instituição possa fomentar a sua longevidade ao atender as necessidades dos seus clientes com o menor gasto de insumos possível, diminuindo o impacto ambiental. Tais direcionamentos asseguram, à longo prazo, uma operação menos custosa, ajudam a construir uma relação benéfica entre a empresa e a comunidade - criando laços importantes para o desenvolvimento institucional e da região - e ainda, melhoram a imagem da corporação junto ao público e demais agentes socioeconômicos, elevando o seu valor e o apreço para com a sua marca e seus produtos.

\section{PRODUTO LOCAL}

Como falado, o objetivo do presente trabalho é mostrar como o pensamento estratégico e a utilização da abordagem do DE na concepção de um SPS - em toda sua amplitude - podem ser usados na construção de valor para produtos de natureza local. Esses produtos, considerados parte integrante fundamental da identidade de uma região, possuem um potencial natural enorme, já sendo, inclusive, responsáveis pela subsistência de várias comunidades mundo afora. Entende-se, portanto, que utilizar as premissas e direcionamentos do DE pode ser uma valiosa alternativa para melhor construir as ofertas locais, consequentemente gerar valor para os produtos, suas marcas e a própria imagem do território de origem, trazendo ganhos diretos e indiretos que serão fundamentais para a prosperidade socioeconômica da região e de seus habitantes.

Figura 2: Qualidades potenciais do produto local.

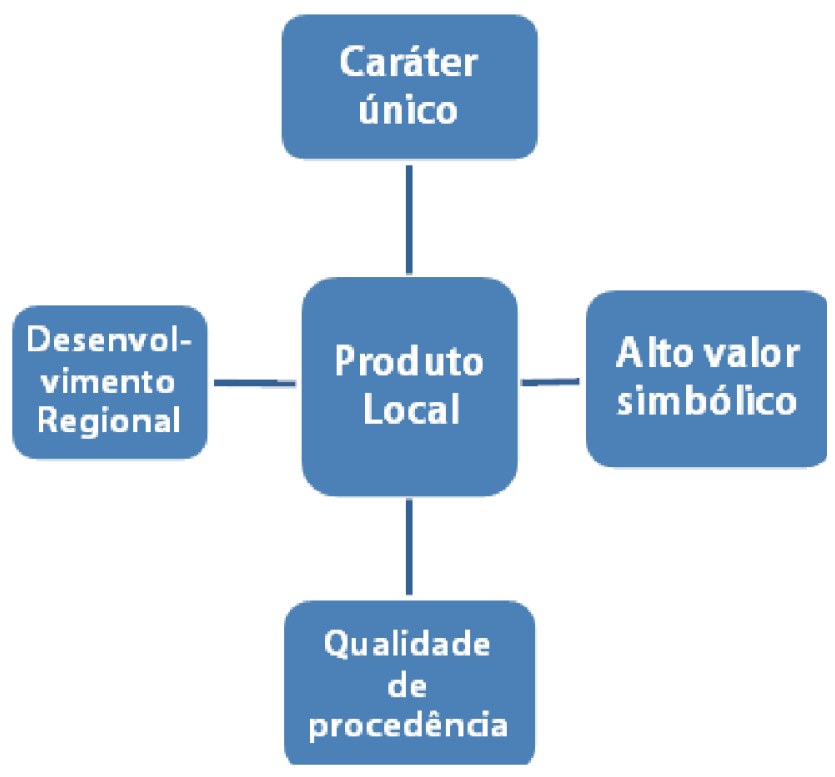

Fonte: Autores 
Tendo em vista que os recursos tangíveis e intangíveis locais podem servir de motores para o desenvolvimento de uma região, o Brasil apresenta-se como um "produto" de alto potencial.

Os países megadiversos, como o Brasil, possuem uma grande riqueza de culturas e etnias e também de recursos da biodiversidade. Essa riqueza constitui a base para o desenvolvimento de produtos fortemente ligados à origem e à comunidade local. [...] estimular o reconhecimento das qualidades e dos valores relacionados com um produto local - qualidades referentes ao território, aos recursos, ao conhecimento incorporado na sua produção e à sua importância para a comunidade produtora - é uma forma de contribuir para tornar visível à sociedade a história por trás do produto. Contar essa "história" significa comunicar elementos culturais e sociais correspondentes ao produto, possibilitando ao consumidor avaliá-lo e apreciá-lo devidamente. E significa desenvolver uma imagem favorável do território em que o produto se origina. Essa visibilidade cultural e a diversidade das culturas, sendo desse modo um fator de preservação da herança cultural que receberão os sucessores no uso do

território. Contribui também para a adoção e valorização de práticas sustentáveis na produção, na comercialização e mesmo no consumo. (KRUCKEN, 2009, p. 22/23)

Nesse contexto o Design se apresenta como um importante recurso, não apenas ajudando, operacionalmente, a comunicar os elementos tradicionais de uma região em suas expressões gráficas e promocionais, mas, estrategicamente, para melhor desenvolver toda a cadeia que envolve a produção dos artefatos e a montagem dos serviços, amplificando as características típicas como fatores realmente diferenciados, e atuando no fomento ao Desenvolvimento Regional.

No contexto do presente trabalho, entende-se que o produto de natureza regional, seja ele tangível ou intangível, é um importante fator na equação que considera as variáveis para a busca pelo desenvolvimento e, dessa forma, contribuir para a melhoria de modelos de negócio, direcionamentos gerenciais e a criação de ofertas que amplifiquem as qualidades de bem oriundo e/ou característico de uma região configura-se como uma alternativa interessante para geração de renda, visibilidade e desenvolvimento socioeconômico para o território. A Figura 3 mostra como o Design ser útil às regiões, sendo possível enxergar o papel potencial dos produtos locais nesse cenário.

Figura 3: Possíveis contribuições do Design aos produtos locais e seus territórios.

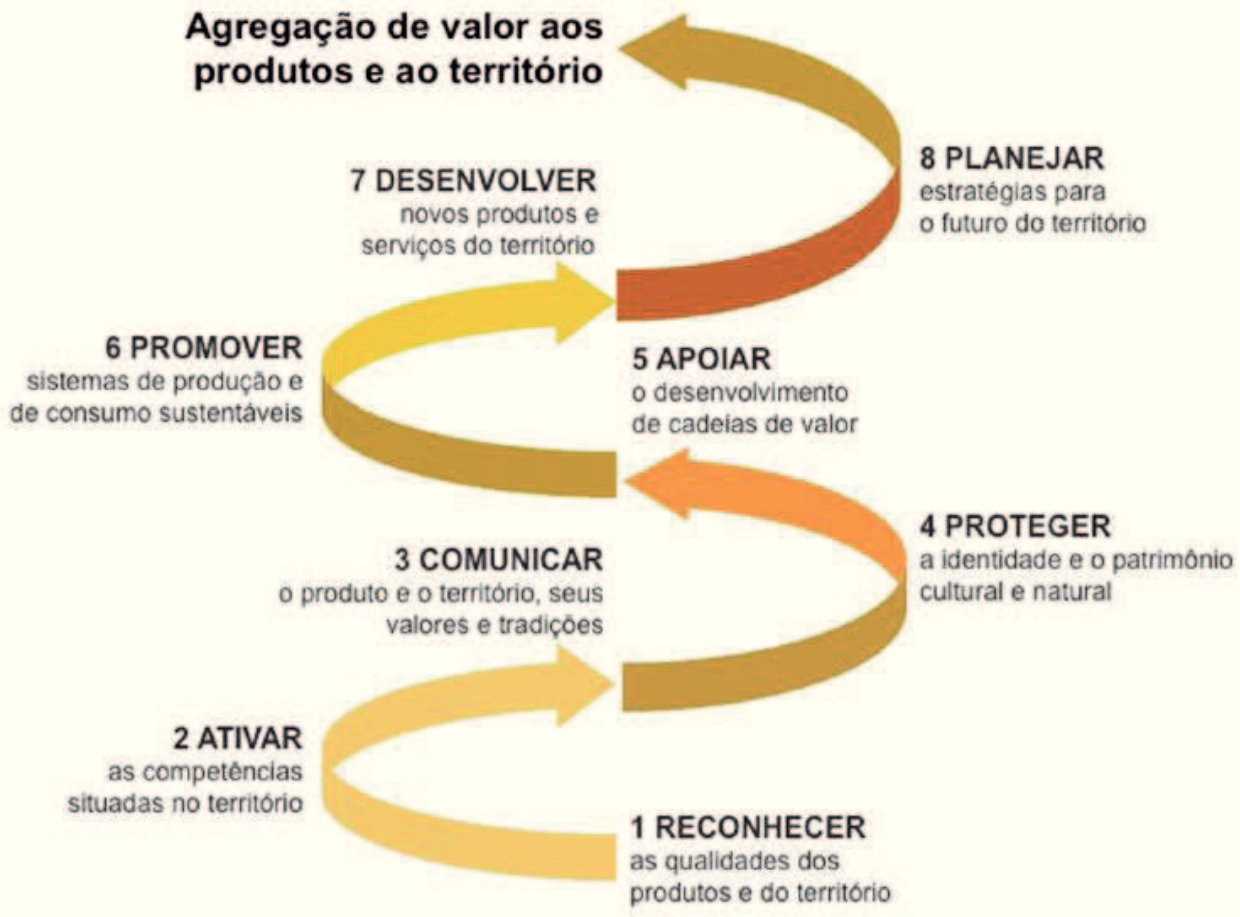

Fonte: FRANZATO; KRUCKEN; REYES (2013) 
Entende-se, assim, que nesse contexto o DE - e o seu foco no SPS - oferece uma abordagem capaz de entender e interpretar os traços típicos de uma cultura, utilizando-os como insumo fundamental já no diagnóstico e planejamento estratégico das organizações (em toda a sua abrangência e complexidade), na criação de uma oferta que melhor traduza o conceito escolhido na forma de uma solução que ofereça uma experiência memorável e de alto valor para o cliente, e, finalmente, no correto e coeso estabelecimento de uma comunicação entre o público e a marca, a partir de pontos de contato cuidadosamente escolhidos e um discurso inteiramente alinhado e verdadeiro à identidade estratégica proposta pela empresa no início do processo.

Logo, utilizando uma abordagem de Design Estratégico, é possível que uma organização de qualquer natureza, porte, origem e setor - consiga identificar, valorizar e transformar os seus valores tangíveis e intangíveis em produtos, serviços e/ou experiências diferenciadas e apreciadas pelos consumidores, ao mesmo tempo que, apoiando sua cultura regional, proporciona orgulho e engajamento da sua comunidade, criando uma oportunidade ímpar para implementar um plano de desenvolvimento sustentável da cadeia produtiva e de preservação do patrimônio natural, material e imaterial local.

\section{O CASE SAMBAZON}

Buscando demonstrar como, na prática, a sintonia entre estratégia e design podem produzir empreendimentos de sucesso com base em modelos de negócio sustentáveis e que resultam na valorização dos produtos locais e de sua região como um todo, será apresentado um breve relato sobre a empresa norte-americana de produtos derivados de açaí Sambazon.

Um dos critérios iniciais da escolha do case era que ele tivesse como insumo base um APL e oriundo de recursos da biodiversidade, de preferência com múltiplas aplicações em diferentes tipos de mercado, em razão do crescimento da sua aceitação pelo público e pela sua capacidade de - quando bem projetados - servir como veículo para a divulgação de traços culturais de uma região bem como o território em si, podendo tornar-se até um importante gancho para atração de investimentos e turismo (KRUCKEN, 2005; KOTLER et al., 2006).

Neste sentido, em meio a pesquisas de vários produtos tipicamente brasileiros, como o guaraná ou a cachaça, por exemplo, encontrou-se no açaí um insumo de alta relevância e potencial em razão de sua crescente penetração no mercado brasileiro - seja como produto final ou como componente de cosméticos, refrigerantes etc. - e pelo conhecimento prévio do autor, por meio de notícias vinculadas na imprensa, de que o produto já ganhava expansão internacional por meio de produtos variados que estampavam o açaí como uma de suas principais matéria-prima.

A Sambazon é uma empresa californiana concebida a partir da experiência vivenciada por dois turistas norte-americanos apaixonados por surf que, em 1999, viajaram ao Brasil em busca de aventura e ondas na passagem do milênio - eles eram dois dos futuros fundadores da empresa, Ryan Black e Edmund "Skanda" Nichols. Em praias brasileiras, mais especificamente em Porto de Galinhas/ $\mathrm{PE}$, os dois turistas foram apresentados e conheceram os sabores e potenciais energéticos do açaí e imediatamente se apaixonaram pela fruta. Eles rapidamente perceberam, através de algumas pesquisas iniciais, que estavam diante de uma oportunidade para apresentar um novo e poderoso produto ao mercado americano - que não conhecia o fruto, nativo do norte do Brasil - ao mesmo tempo que podiam ajudar na preservação da Amazônia e no desenvolvimento econômico das comunidades locais. (MUNDO DAS MARCAS, 2015)

A partir desse desejo, foi tomando forma o conceito da marca. Tal conceito foi elaborado a partir de um modelo de negócios com 3 pilares: People, Planet, Profit (Pessoas, Planeta e Lucro) e tem na sustentabilidade a sua grande essência. Esse modelo, chamado Triple Bottom Line (TBL), foi cunhado pelo consultor britânico John Elkington (THE ECONOMIST, 2009).

O modelo de negócios, com um viés sustentável, provou-se importante para o desenvolvimento da empresa e, especialmente, para a viabilização do negócio de maneira a mais do que não agredir, mas preservar e apoiar o território e seus habitantes. A empresa foi a primeira a exportar legalmente o fruto para os EUA e a registrá-lo no FDA (Food and Drug Administration), respeitada agência que controla o comércio de alimentos e remédios nos Estados Unidos.

Em meados de 2006 a Sambazon construiu uma indústria de beneficiamento em Santana, no Amapá, onde cerca de 80 funcionários trabalham na transformação das frutas em polpa. Esse passo foi fundamental para que a empresa pudesse cumprir sua promessa de ser $100 \%$ orgânica, pois o açaí é um fruto que rapidamente se estraga, logo o seu processamento deve ser feito o quanto antes. Com o objetivo de cortar os intermediários e trabalhar diretamente, e, consequentemente, ter a oportunidade de contribuir mais - com os agricultores familiares locais, foi tomada a decisão estratégica de investir em uma fábrica 
que garantiria a qualidade do produto e geraria benefícios socioeconômicos para a comunidade.

Como resultado desses esforços, o governo americano, concedeu o Award of Corporate Excellence (A.C.E Award) à Sambazon - após indicação do embaixador dos EUA no Brasil - "por seu trabalho com a população de origem indígena na Amazônia brasileira". O prêmio foi entregue pela então secretária de Estado do país, Condoleeza Rice, que afirmou que a empresa "é um exemplo extraordinário do impacto positivo que uma pequena empresa pode trazer à economia, ao meio ambiente e à sociedade que os abriga". Ainda segundo Rice, a Sambazon foi escoIhida por "seus esforços em promover o desenvolvimento sustentável da floresta brasileira, ao mesmo tempo que melhora as condições de vida da população local através do marketing criativo do açaí" (OPIC, 2015).

A empresa, que nasceu da visão de dois turistas americanos encantados com um fruto típico da Amazônia brasileira cresceu e prosperou sem perder os seus valores, ao contrário, valorizando-os ao realizar o design de seu SPS. A companhia iniciou seu processo de internacionalização, introduzindo seus produtos na Ásia, no Canadá e, de maneira ainda discreta, no Brasil a partir de 2013. Hoje a companhia conta com cerca de 200 funcionários, sendo cerca de $50 \%$ no Brasil, um faturamento estimado de cerca de U\$200 milhões e está presente em 8 países, incluindo Austrália, México, Japão - onde também já instalou um SAC, e Coréia do Sul, e nas principais redes de varejo dos EUA. Seus produtos são vendidos em mais de 20 mil pontos de distribuição, sendo atualmente a quinta maior marca de sucos na categoria premium do mercado americano. (MUNDO DAS MARCAS, 2015)

\section{CONCLUSÕES}

Buscou-se, ao longo deste trabalho, intensificar uma reflexão do papel do Design como um recurso que imprime valor a empresas e produtos de maneira a viabilizar a criação e aplicação de modelos de negócio sustentáveis, onde o produto regional tem a capacidade de tornar-se diferenciado e um motor de desenvolvimento à sua localidade de origem.

Considerando que o Design Estratégico tem como premissa o fomento a um Sistema Produto-Serviço que movimenta diversos atores mercadológicos e sociais na busca do desenvolvimento sustentável a partir de iniciativas inovadoras (MERONI, 2008), identificou-se na Sambazon um bom exemplo prático e real de como uma iniciativa privada, criada a partir de um conceito e montada estrategicamente para cumpri-lo, pode trazer benefícios econômicos, sociais e ambientais para toda a cadeia envolvida no negócio. Sob esse aspecto também se destaca o caráter colaborativo que a empresa imprime, aliando-se a uma série de agentes institucionais (universidades, governo, institutos etc.) para fortalecer o seu modelo de negócio e estabelecer uma interface entre a companhia e a comunidade local ao mesmo tempo que promove ações e capacitações que visam preservar o ecossistema de onde vem o seu insumo base.

Sendo considerado uma abordagem transversal, e não um método, (IKEDA, 2008; FRANZATO, 2010), o DE não traz para esse trabalho passos a serem seguidos, mas sim serve como direcionamento para identificar no case escolhido - e fornecer insights aos demais empreendedores e executivos -, a concepção de um modelo de negócios e de uma gestão estratégica, que busca, através do Design do seu Sistema Produto-Serviço, atender as necessidades do consumidor e promover desenvolvimento sustentável para a empresa e para a região de onde são extraídos os seus insumos.

\section{REFERÊNCIAS}

BEZERRA, P. F. M. Design Estratégico e Branding: valorizando experiências e produtos locais - o caso Sambazon. Dissertação de Mestrado. Universidade Federal de Pernambuco, Recife, 2016.

BONSIEPE, G. Design, cultura e sociedade. São Paulo: Blucher, 2011.

BONSIEPE, G. Design do Material ao Digital. São Paulo: Blucher, 2015.

COSTA, E. A. Gestão Estratégica: da empresa que temos para a empresa que queremos. 2 Ed. São Paulo: Saraiva, 2007.

FRANZATO, C. O Design Estratégico no Diálogo entre Cultura de Projeto e Cultura de Empresa. Strategic Design Research Journal, v. 3, p. 89-96. Porto Alegre: Unisinos, 2010.

FRANZATO, C.; KRUCKEN, L.; REYES, P. B. Design for territorial development in emerging economies: Brazilian experiences of researching and teaching. Strategic Design Research Journal, 6(1): 11-19, Jan-abr. Porto Alegre: Unisinos, 2013. 
FREIRE, K. Design Estratégico para Inovação Cultural e Social. São Paulo: Kazuá, 2015. GIL, A. C. Métodos e Técnicas de Pesquisa Social. São Paulo: Atlas, 2008.

HITT, M. A; IRELAND, D. R; HOSKISSON, R. E. Administração Estratégica: competitividade e globalização. 2 Ed. São Paulo: Cengage Learning, 2011.

IKEDA, M. Strategic Design. In: M. ERLHOFF; T. MARSHALL. Design Dictionary: Perspectives on Design Terminology. Basel, Birkhäuser, p. 373-376, 2008.

KOTLER, P., \& KELLER, K. L. Administração de Marketing: A Bíblia do Marketing. São Paulo: Pearson Prentice Hall, 2006.

KOTLER, P. et al. Marketing de lugares: como conquistar crescimento de longo prazo na América Latina e no Caribe. São Paulo: Prentice Hall, 2006.

KRUCKEN, L. Design e Território:Valorização de Identidades e Produtos Locais. São Paulo: Studio Nobel, 2009.

MANZINI, E; VEZZOLI, C. Product-Service Systems and Sustainability. Paris, UNEP, 2002. Disponível em: http:// www.uneptie.org/scp/Design/pdf/pss-imp-7.pdf, acesso em: 09/09/16.

MERONI, A. Design Estratégico: onde estamos agora? Reflexão em torno dos alicerces de uma disciplina recente. Srategic Design Research Journal, 1 (1): 31-38, jul-dez, 2008.

MOZOTA, B. B. Gestão do Design: Usando o Design Para Construir Valor de Marca e Inovação Corporativa. Porto Alegre: Bookman, 2011.

MUNDO DAS MARCAS. Sambazon. 2015. Disponível em: <http://mundodasmarcas.blogspot.com.br/2010/03/ sambazon.html>. Acesso em 13 de set. de 2016.

OVERSEAS PRIVATE INVESTMENT CORPORATION (OPIC). How One Small Business Helped Make the Rainforest "Too Valuable to Cut Down". 2015. Disponível em: <https://www.feedthefuture.gov/article/how-one-small-business-helped-make-rainforest-\%E2\%80\%9Ctoo-valuable-cut-down\%E2\%80\%9D>. Acesso em 21 de out. de 2016.
THE ECONOMIST. Triple Bottom Line. 2009. Disponível em: <http://www.economist.com/node/14301663>. Acesso em 28 de out. de 2016.

VIEIRA, E. T; SANTOS, M. J. Desenvolvimento econômico regional - uma revisão histórica e teórica. In: Revista Brasileira de Gestão e Desenvolvimento Regional. V. 8, n. 2, p 344-369, mai- ago 2012. Taubaté, São Paulo, Brasil, 2012. 